below, and also through the abdominal ring above. On dividing the canal up to the external ring, I was enabled to introduce my forefinger into the abdomen, and with its point I could just touch what appeared to be the lower part of a knuckle of distended intestine, to reach which it was necessary to enlarge the opening which I had made; this I did by extending my incision npwards and slightly outwards, dividing some of the fibres of the tendon of the external oblique, and was thus enabled to introduce two fingers to a considerable distance, and to find a large knuckle of bowel in a very distended state, but still too distant to lay hold of. It became necessary, therefore, to extend the incision still further, which was done in the same direction, dividing the internal ring, and some of the Iower fibres of the internal oblique and transversalis muscles. The opening thus made gave me room enough to introduce three fingers, which which I could now lay hold of the portion of intestine, and draw it down through the wound. It proved to be a strangulated coil of small intestine, ten inches long, of a deep red colour, with ecchymosed patches on the surface. On pulling upon the protruded bowel, and introducing my finger, I found that it was tightly constricted by the omentum, which was loaded with fat, and through an opening in which, either natural or caused by adhesions, the intestine had found its way, and become strangulated. The stricture was very tight; at first I could only introduce my nail under it, but by degrees I got the end of my finger through, and $I$ hoped to be able to dilate the opening sufficiently to return the protruded bowel, but as the stricture was dense and hard as ligament, I found it impossible to do so, and as I could yot draw down the omentum, $I$ introduced a wide director on my finger under the stricture, and with a blunt-headed bistoury I freely divided it. This, happily, was not followed by any hæmorrhage. I therefore proceeded to return the gut back through the enlarged aperture. This I found extremely difficult to do, for as fast as I returned a portion, a greater volume escaped, and it was only by patience and good assistance that I was able to return the whole; but had the intestines generally been distended with flatus, I think it more than likely that I should not have succeeded in restoring the displaced bowel without having recourse to acupuncturation to give exit to the flatus, as in a case I described on a former occasion, ${ }^{*}$ in which a large opening through the abdominal parietes had been made, and the protruded bowel had, with difficulty, been put back. The head of the colon, on account of the size of the opening, rotating upon its short mesocolon, escaped towards the close of the operation, and was not returned without the usual difficulty attending the reducing of this part. All, however, was satisfactorily replaced; no hæmorrhage of any amount occurred, one small artery alone being tied. The edges of the wound were brought together by sutures, and dressed with a compress of several folds of linen, and fixed by a spica bandage. The patient underwent the operation without chloroform, as Mr. Allen did not consider him an eligible patient for taking it, and felt very little fatigue or the worse for the operation.-One P.M. : Two copions liquid evacuations passed; the patient felt greatly relieved, but the hiccup still continued.- Three P.M.: We met in consultation, and found the patient as follows:-Pulse 130; skin hot; tongue white and loaded; no pain. Ordered the following pills: Chloride of mercury, two grains; opium, one grain-to be taken immediately; and two hours afterwards, another composed of one grain of calomel, and half a grain of opium, every two hours. - Nine P. M. : Patient much the same; hiceup very dis tressing; pulse feeble, but quick. Ordered the following mix. ture:-Sesquicarbonate of ammonia, twelve grains; essence of peppermint, twenty minims; camphor mixture, five ounces and a half; compound spirit of sulphuric ether, two drachms: mix; one-fourth every four hours. Mr. Allen saw the patient every two hours after the operation, up to two A.M.

19th. - Nine A.M. : I met Mr. Allen in consultation, and we found the patient had had a bad night, the hiccup being very troublesome, and he was very low; abdomen distended; tongure white and loaded; skin hot; pulse 130 and wiry; pain in right hypochondriac and iliac regions, and tenderness on pressure. Ordered the application of ten leeches, and afterwards a large linseed poultice, and the following draught and powders:Battley's sedative solution, thirty minims; spearmint water, one ounce and a half; to be taken immediately. Calomel, four grains; powdered loaf sugar, four grains : mix into four powảers, one to be taken every three hours, -Nine P.M. : The symptoms much relieved; great flatulence; no evacuation of the bowels; much depression. A rue enema was given, and a draught of ether and ammonia ordered every three hours.

20th-Nine A.M. : The injection had procured two copious evacuations, with much escape of flatus, from which much relief was felt. Pulse 120, soft and compressible; vomiting had ceased, but the hiccup continued with but slight intermissions. -Nine P.M. : Symptoms of bronchi pneumonia have come on in the right lung with much severity, together with slight delirium tremens, symptoms of which have shown themselves ever since the opiate draught of yesterday. Pulse soft and quick. tongue white and flabby. Vinegar of cantharides was applied between the scapulæ and over the chest; two active aperient pills were administered, and the calomel omitted.

2lst.-Two A.M.: An enema was given, which was followed by two evacuations; hiccup recurring slightly at intervals; pulmonary symptoms severe, with considerable depression. Ordered the following mixture:-Decoction of senega, five ounces and a half; chloric ether, one drachm and a half; distilled vinegar, half an ounce: mix, a fourth part to be taken every four hours. Beef-tea to be given frequently. Vesication kept up over the chest with the vinegar of cantharides. By these means the symptoms were subdued, though we considered our patient in great danger for a day or two. The wound in the meantime proceeded most favourably, and appeared to be healing by the first intention.

22nd.-Sutures removed; wound nearly closed.

24th. - The patient was so far recovered, and the wound so nearly healed, that I took my leave.

Mr. Allen has since informed me, that on the 26th, some symptoms like gout came on, and lasted several days, and that the wound opened and suppurated, leaving a small sinus; this, however, closed after some days under the pressure of a truss with a broad pad, and the patient resumed his usual occupation.

There were many instructive points about this case, such as the ambiguous signs of strangulation; the loose, large, irreducible hernia on the left side, which was justly considered to be in nowise connected with the symptoms; the absence of pain or tenderness on the right side, or any other symptom than the slight pain occasioned by traction of the testis, to indicate the seat of the stricture. Also, the absence of bleeding after dividing the stricture in the omentum, which, had it occurred, as I fully expected it would, might have proved very troublesome, and the vessels would not have been secured with. out much difficulty. Then the attack of bronchitis with pneumonia, and slight delirium tremens, in which depletion could not be resorted to, but which happily yielded to extensive counter-irritation and stimulating expectorants; and, lastly, the long and obstinate continuance of hiccup, which did not entirely subside for a week, from the first symptoms of strangulation, and which at last yielded more to the effects of the vesication than anything else. These, and other minor points, rendered the case sufficiently interesting and anxious.

George-street, Hanover-square, 18as.

ON A

\section{SUCCESSFUL CASE OF EXCISION OF THE} KNEE-JOINT.

By P. C. PRICE, Esø., M.R.C.S.,

SUBGEON TO THE GREAT NORTHERN HOSPITAI; TO THE METROPOLITIY INSTITUTYON FOR SCROFULOUS CHIXDREN AT YARGATE, ETC.

Tue details of another case in which I lately excised the knee-joint on account of long standing and very extensive disease, may, perchance, tend to modify opinions not unfrequently advanced against the utility and advantages of the operation, while a further statement of success cannot fail to be productive of interest and instruction:-

J. M. S-, aged fifteen, born at Manchester, inheriting a thoroughly strumous constitution, was, at an early age, left an orphan. Ill-nourished and neglected, she obtained admittance into a London workhouse, and, at various periods, was removed into its infirmary on account of sickness. About five years since, when ten years of age, she remembers having struck her right knee, and that the accident was followed with very considerable pain, swelling, and the formation of matter. In due time, however, the use of the joint was recovered, and she remained in tolerable health till, unfortunately, the knee again received an injury, which compelled a second entrance into the infirmary. Iodine paintings, blisters, and rest removed the local distress, while a subsequent residence at a sea-side institution served to repair her shattered constitution. 
In the month of October, 1855 , she was sent to Margate, and there came immediately under my notice. Owing to the excellent management adopted at the institution in which she was placed, the general condition greatly improved, while the local disturbance remained in abeyance.

In April, 1857, unfortunately an accident awakened the disease that seems to have remained latent in and about the joint. This last mishap was followed with considerable pain, and although immediate rest on a splint was observed, the distress in the course of a few days appeared greater than on previous occasions. Swelling of the joint, with constitutional symptoms, pointed to the severity of the present relapse; and as irritants had previously been of service, they were again resorted to. Iodine, blisters, and the actual cautery certainly tended to abate the pain, but the benefit was only temporary. The character of the swelling, careful manipulation, and other features, pointed to the lower end of the femur as the chief site of the local mischief. After the lapse of a few months, a fistulous opening appeared on the outer side of the knee, through which flowed an unhealtiny secretion. A probe passing along this fistulous canal reached the interior of the articulation. It was now evident that considerable mischief was taking place in the structures composing the upper portion of the joint. For many weeks the child suffered excessively; the spirits drooped, the health rapidly gave way. Constant pain, starting of the limb, night-sweats, with shivering, plainly told the necessity for more decisive measures. Procrastination was dangerous, and the mere entertainment of hopes delusive. The child most willingly submitted to any operation I might think best suited to her case. Two proceedings appeared admissibleamputation and resection. The latter seemed the more correct, as it was not only in accordance with the principles of modern surgery, and was fraught with less risk to life, but it was an operation in every way more humane, and calculated to insure to the patient the retention of a limb useful and free from disease.

Dec. 7th, 1857. - The child having been placed under the influence of chloroform, a semilunar flap of integument was turned upwards. This reflected portion consisted chiefly of skin, the avoidance of other tissues being desirable. The lateral incisions, as is my usual plan, were carried as far back as possible. On opening the joint cavity, the chief mischief appeared to occupy the back portion of the condyles of the femur, as the articular cartilage was destroyed to some extent. Slight pressure with the fingers served to break down a weak barrier of thinned cartilage, which separated a large cavern in the outer end of the femur from the articulation. The application of the saw to the condyles allowed the escape of a quantity of un healthy pus, containing debris of carious bone. The destruction to the osseons substance of the lower end of the femur, and especially that portion corresponding to the external condyle, appeared so extensive, that some gentlemen who witnessed the operation thought it more expedient to resort to the amputating knife. Experience had, however, taught me otherwise; and althongh a very considerable cavity remained after a free use of the gouge and scoop, still it seemed but right to give the patient every available chance of retaining a serviceable limb. A free and healthy bleeding from all parts of the cavity gave a tolerable assurance that the majority, if not the entire amonnt of disease had been removed. The head of the tibia was to all appearance unaffected, and, therefore, the mere removal of the articulating cartilage snfficed.

I have on other occasions advised the removal of the patella, even if it be not included in disease, as its retention is not un frequently fraught with considerable mischief. I cannot recollect any great advantage having been gained in any special instance in which the bone was allowed to remain, and from the subsequent inconvenience and suffering $I$ have seen more than once to occur in cases in which it was saved, I now invariably take it away.

The hæmorrhage, perhaps, was more copious than usual, owing to the free bleeding from the lower end of the femur. The cut surfaces came strictly into apposition. A few points of suture restored the flap to its adjacent parts, while the cavity in the lower end of the thigh-bone was plugged with strips of lint. The limb was accurately placed upon the splint I am in the habit of using before the patient was removed from the operating table. I cannot too urgently insist upon the importance of this step, for I have seen the most disastrous consequences ensue from its non-observance.

I noticed that, in this instance, the shock from the operation was greater and more lasting than on any previous occasion in which I have resorted to resection of this articulation. I attribute this additional disturbance to the somewhat protracted time the operation required for correct performance, and to the low condition into which my patient had fallen from acute and lengthened suffering. The continuance for a day or two of an obstinate nausea and vomiting was, perhaps, somewhat dependant upon the inhalation of chloroform, although, in all probability, the shock to the nervous system would offer sufficient explanation. Some slight oozing took place from the bone, which was, however, controlled by means of cold appli. cations used externally.

In a few days suppuration commenced, and after the floating away of some unhealthy material, composed of the débris of bone and altered blood, the discharge became healthy. The wound was treated in accordance with the principles of sur. gery, and the patient, after the first few days, began rapidly to improve. Freedom from sleepless nights caused by almost intolerable pain, the return of the appetite, and increasing good spirits, tended to advance her recovery.

The limb was allowed to remain for seven werks without being once shifted or removed, in any way, from the position in which it was placed at the time it was dressed upon the ope. rating-table, and only once again was it cleansed before a gutta-percha splint was substituted for the apparatus in which it had remained for so many weeks.

I would again impress upon all surgeons who undertake the operation this great secret of success. A close acquaintance with the rise and progress of this special proceeding has convinced me of the extreme importance of meddling as little as possible with the limb when once it is placed in an accurate position. I have seen death supervene entirely from bad management. Amputation has frequently been necessary. Protracted and imperfect recovery has still more often followed a misunderstanding of this highly important feature.

The daily management of the case fell to the care of my brother, Mr. William Price; and to the extreme interest be took in following out my method of treatment the patient is much indebted for a rapid recovery.

On the 23rd of March my brother writes: "The wound has quite bealed, one little sinus on the front of the lex, together with the old-existing one on the outer side, being the only open sores. The discharge is so slight that the parts only require to be dressed twice a week. She can bear a considerable pressure upon the leg, and is up and out every day. The shortening is comparatively slight, and the anchylosis osseons and remarkably firm. The leg is in a perfect line with the thigh, and the case is in everyway highly satisfactory."

Subsequently I have seen the child, and her condition, in every respect, is certainly all that could be desired.

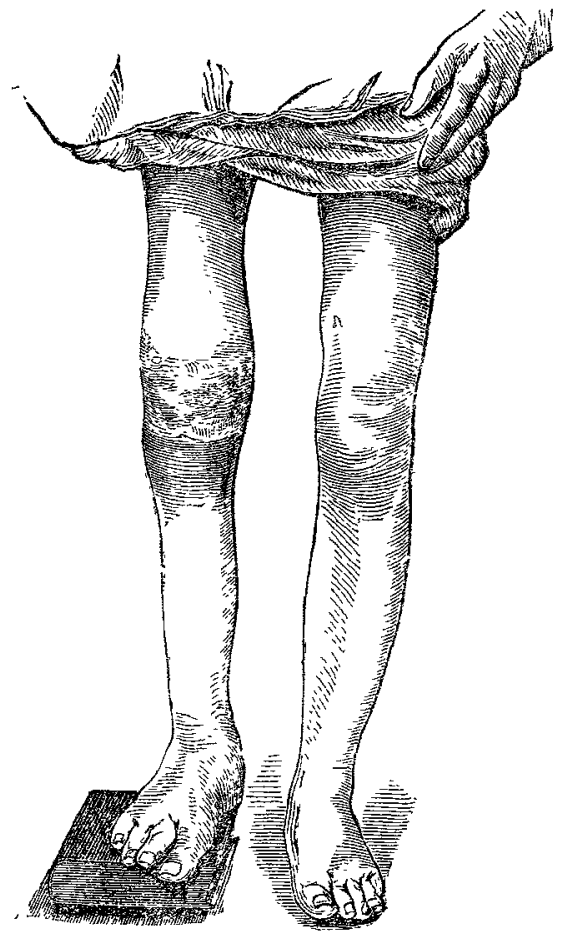

The accompanying woodcut is drawn by Dr. Westmacott, from a photograph taken by Mr. Hicklin, six months after the operation. It faithfully represents the condition of the patient's lower extremities. The swelling of the right ankle is a feature often observed after removal of the knee-joint.

There is one point in connexion with the operation that was performed of extreme pathological interest: the rapid repara. 
tion that followed the removal of the carious bone. It has been asserted by some surgeons that osseous consolidation between two or more bones entering into the formation of an articulation, when affected with disease or some special inflammation, is of rare occurrence, and that after removal of a destroyed articulation by the operation of resection, anchylosis by bone material is by no means a frequent result. Every-day experience, and information afforded by museums, must satisfy the most incredulous of the erroneousness of such assertions; whilst everyone, who is at all acquainted with the history of resections of the knee, knows that cure by osseous anchylosis is the rule and not the exception. It has often fallen to my lot to see the great efficiency of Nature in repairing bone structure which has been implicated by strumous disease; and the highly satisfactory result that has followed in this case will give me additional reason for resorting to excision of a vitiated joint, even when more extensively destroyed.

Grcen-street, Grosvenor-square, 1858.

\section{ब.}

OF THE PRACTICE OF

\section{MEDICINE AND SUPGERY IN THE}

\section{HOSPITALS OF LONDON.}

Nulla est alia pro certo noscendi via, nisi quam plurimas et morborum et Æissectionum historias, tam aliorum proprias, collectas habere et inter se comparare.-Morgagn. De Sed. et Cans. Morb.lib.14. Promium.

\section{ST. BARTHOLOMEW'S HOSPITAL.}

\section{MIYELOID DISEASE OF THE HEAD OF THE TIBIA. AMPUTATION AT THE THIGH.}

(Under the care of Mr. STANLEY.)

$M$ M. STANLey has remarked, in his work on "Diseases of the Bones," that there is a sort of special predisposition in the head of the tibia to become diseased. On the $22 \mathrm{nd}$ of May, a singular case was brought into the theatre for operation, upon which no positive opinion could be pronounced by Mr. Stanley or his colleagues. A healthy, stout, robust, and vigorous man, endowed, apparently, with great muscular strength, had a small, flattish sw 1ling, about two inches and a half in diameter, over the anterior surface of the head of the right tibia, a little below and to th. inner side of the tubercle. It was covered with two or thi ee prominent veins, felt slightly soft, and had been slowly growing for some ten months. An incision was made around it at its outer margin, of a semicircular form, the skin dissected off, and the tumour sliced off at its base, when it was found to present a malignant aspect. This was attended with much bleeding, and on further examination, it was discovered that the tumour covered the opening leading into a large cavity in the head of the tibia, filled with a quantity of soft plastic material, and from which poured out a great deal of blood. This cavity extended quite close to the joint. A consultation was immediately held, and it was deemed advisable to amputate through the thigh, which was accordingly done by the circular operation. A curious circumstance now happened: the main trunk of the femoral was secured, but no bleeding from any other vessels appeared on loosening the tourniquet, the man's pulse being at the same time pretty good. He was therefore removed, and the stump watched by the dresser.

A careful dissection and minute examination of the disease were made in this case, when it was ascertained that the disease in the tibia was myeloid, possessing the true characteristics of that affection.

During the operation upon this patient, it was assumed that there was malignant disease of the tibia, and, under the peculiar circumstances of the case, amputation was resorted to. That proceeding was the proper one, even had it been known that myeloid disease was the form of malady present, for it had engaged almost the whole of the head of that bone, and so rendered the limb utterly useless.

The question of malignaney in many of these doubtful cases is one of very great importance to the suffering patient, and if it can be satisfactorily determined otherwise, there is ground for promising an immunity from further disease. Some valuable remarks upon some "Diseases of the Bones," by Dr. Wilks, in a recent volume of "Guy's Hospital Reports," furnish much information on this subject. Osteo-sarcoma is believed by many surgeons to be a harmless disease. He, however, places it as intermediate between cancer and myeloid tumours. Cancer, in its most marked forms, involves the whole bone, from joint to joint, whereas the harmless myeloid tumours are quite round and circumscribed, and osteo-sarcoma is intermediate in position. Twelve eases of myeloid diseases of bone are given in Dr. Wilks' paper, three of them engaging the head of the tibia. The first of these would seem to be the counterpart of Mr. Stanley's case, only in a somewhat more ad ranced degree, a large cavity occupying the head of the tibia, which had been filled by a "fungoid growth." A fibrous network runs throughout from the cyst on all sides, and in the meshes is de. posited the peculiar marrow-like substance.

The remarkable peculiarity of myeloid tumours, as we have mentioned in former "Mirrors," (THE LA_cet, vol. i. 185t, p. 524 and 602 ,) is, that when the tumours, or the limbs affected with them, are removed, they do not return; and if the patient should succumb after the operation, no other morbid growths have been found in the body. Dr. Wilks's researches in this respect agree with those of Mr. Henry Gray, Mr. Paget, and other observers of this truly interesting disease.

\section{ST. MARY'S HOSPITAL.}

WOUND OF CORNEA, SCLEROTIC, AND IRIS, FROM AN IRON SCREW WEIGHING TWELVE GRAIYS, WHICH WAS SUBSEQUENTLY EXTRACTED.

(Under the care of Mr. WHITE Cooper.)

Tres ophthalmic wards of St. Mary's Hospital have lately presented the following cases of considerable interest:-

A deaf and dumb lad, aged eighteen, was admitted. on the 13th of April, 1858. Three weeks previously, whilst working a screw cutting-machine in a manufactory at Derby, a fragment of iron struck his eye with great force, and, inflicting a large wound, instantly blinded it. The same evening he was seen by Mr. Baker, of Derby, who took charge of the case, and treated it with much skill for three weeks, at the expiration of which time he was sent to St. Mary's Hospital. On his arrival, the eyeball was found considerably diminished in size, and presenting a large wound, involving the cornea and sclerotic. The iris was implicated in the wound, and there was no trace of pupil. The lad was in a wretched state of debility, mainly from poverty, and the treatment adopted was simple cold dressings with belladonna to the eye, good diet, and steel with quinine internally. Under this treatment, the eye progressed favourably, the pain and inflammation subsided, and cicatrization proceeded satisfactorily.

On Saturday, May Sth, Mr. White Cooper observed that a dark-brown point had made its appearance in the wound, and expressed his opinion that it was metallic, which a touch with a probe proved to be the case. He tried to remove it with forceps, but finding that it was firmly impacted in the eye, he ordered the patient to the operating-theatre, and proceeded to extract it under chloroform. Having made an incision through the cornea and iris in their whole breadth, he seized the foreign body, and with some difficulty withdrew it. It proved to be a piece of iron screw, four lines in length by three in breadth, and weighing twelve grains. Its elges were extremely jagged and sharp, and the surface irregular. Fotwithstanding the violence inflicted on the eye by the withdrawal of this mass, scarcely any irritation followed, and on the following Tuesday the lad was able to leave his bed, and walk about the ward.

It is evident that at the time of the accident the fragment of iron ent through the cornea and iris, and buried itself out of sight. It is most remarkable that such a mass, of a form so calculated to excite irritation, should have caused so little, that even pain, the most common and most annoying of all symptoms attending the presence of foreign bodies in the eyeball, should have subsided, and the wound cicatrized; that it 